\title{
Prevention of Enamel Adjacent to Bracket Demineralization Following Carbon Dioxide Laser Radiation and Titanium Tetra Fluoride Solution Treatment: An In Vitro Study
}

\author{
Amir Hossein Mirhashemi ${ }^{1}$, Sina Hakimi ${ }^{2}$, Mohammad Sadegh Ahmad Akhoundi ${ }^{*}$, Nasim Chiniforush ${ }^{3}$ \\ ${ }^{1}$ Dental Research Center, Dentistry Research Institute, Department of Orthodontics, Tehran University of Medical \\ Sciences, Tehran, Iran \\ ${ }^{2}$ Azad University, Tehran, Iran \\ ${ }^{3}$ Laser Research Center of Dentistry, Dentistry Research Institute, Tehran University of Medical Sciences, Tehran, Iran
}

\author{
*Correspondence to \\ Mohammad Sadegh Ahmad \\ Akhoundi, DDS; School of Dentistry, \\ Tehran University of Medical \\ Sciences, Kargar Shomali Street, \\ Tehran, Iran. \\ Tel: +98-982188994824 \\ Fax: +98-982188994824 \\ Email: ahmadakh@tums.ac.ir
}

Published online 18 July 2016

\begin{abstract}
Introduction: The aim of this study was to assess the caries-preventive potential of carbon dioxide $\left(\mathrm{CO}_{2}\right)$ laser application in conjunction with the use of titanium tetra fluoride solution on the enamel adjacent to bracket.

Methods: Seventy-five freshly extracted bovine incisors were used. In order to attach the brackets, the area of examination was covered with adhesive tape to limit acid etching of the entire enamel surface. Metal orthodontic brackets for upper central were bonded to all the teeth following the manufacturer's instruction. Then all the teeth were painted with 2 layers of acid-resistant nail varnish on all surfaces except the boxes area cervical to the brackets. The teeth were then randomly divided into five groups $(n=15)$ : control group (C); laser group (L); titanium group (T); laser-titanium group (LT) and titanium-laser group (TL). The laser-titanium group was first irradiated with $\mathrm{CO}_{2}$ laser (same as the $\mathrm{L}$ group) then TiF4 solution was applied on the enamel (same as the T group). Samples in the TL group were first treated with TiF4 solution (same as the T group) and then irradiated with $\mathrm{CO} 2$ laser on the surface (same as the L group). Then, the teeth were immersed in $\mathrm{pH}$ cycling solutions. After that, the amount of calcium released into the two solutions (de- and re-mineralization) was measured with an atomic absorption spectroscopy. The data were analyzed by one-way Analysis of var-iance (ANOVA) and Tukey test.

Results: Calcium loss in LT, TL and T groups were significantly lower than those in the $\mathrm{L}$ and $\mathrm{C}$ groups $(P<0.05)$.

Conclusion: The application of Titanium tetra fluoride $4 \%$ solution on enamel can inhibit as much as $87 \%$ of subsequent caries like lesion progression.

Keywords: carbon dioxide lasers; laser therapy; titanium tetra fluoride; demineralization; caries prevention.
\end{abstract}

\section{Introduction}

Promoting facial and dental esthetics is one of the most important goals of orthodontic treatments. However, a common clinical problem threatening this goal is the presence of unsightly white spot lesions, which need additional cosmetic therapy in some cases. ${ }^{1-3}$ White spot lesions, as previous studies reported, occur for nearly $50 \%$ of patients undergoing orthodontic treatment. These lesions can developed within 4 weeks; normally less than the average time between orthodontic visits. ${ }^{4,5}$

The attempts of orthodontists to reduce demineralization have resulted in limited success for a long time. For instance, although evidences exist on the beneficial effects of dentifrices and/or home use of fluoride solutions, patient compliance with use of these materials as prescribed is problematic. Thus, preventive measures not requiring patient compliance seem to be more appropriate for the typical orthodontic patient. ${ }^{6,7}$

One potential application of laser in dentistry is preventive laser treatment of dental hard tissues to increase their resistance to dental caries. The possibility of making dental enamel more resistant to caries attack by irradiation of a carbon dioxide $\left(\mathrm{CO}_{2}\right)$ laser has been described for the two main wavelengths of 9.6 and $10.6 \mu \mathrm{m}$. The lower surface absorption of the $10.6 \mu \mathrm{m}$ wavelength results in a higher penetration depth and can therefore affect a

Please cite this article as follows: Mirhashemi AH, Hakimi S, Ahmad Akhoundi MS, Chiniforush N. Prevention of enamel adjacent to bracket demineralization following carbon dioxide laser radiation and titanium tetra fluoride solution treatment: an in vitro study. I Lasers Med Sci. 2016;7(3):192-196. doi:10.15171/jlms.2016.33. 
thicker enamel layer. Thus, it has been suggested that the caries-preventive effect obtained with $10.6 \mu \mathrm{m}$ could be the longer-lasting one. ${ }^{8-11}$

In order to increase the caries-preventive effect of laser, researchers began to use it in combination with fluoride containing materials. These combinations seem to show the synergistic effect on enhancing enamel resistance. ${ }^{11-14}$ In recent years, the erosion-inhibiting effect of materials containing fluoride compounds has attracted more attention because they were found to be more effective in reducing erosions. The preventive potential of TiF4 against dental demineralization is related to the formation of an acid-resistant surface coating, the increased fluoride uptake and also the titanium incorporation in the hydroxyapatite lattice. ${ }^{15-21}$

There are still very few studies investigating the caries-preventive effect of $\mathrm{CO}_{2}$ laser and TiF4 together in which the synergistic effect of $\mathrm{CO}_{2}$ laser and fluoride has been seen. ${ }^{3,411}$ However, there are still no consensuses between the researchers on the mechanism of their action on each other. Moreover, to our knowledge none of these studies has considered the effect of these two on the enamel around bonded orthodontic brackets.

Our primary aim was to assess the caries-preventive potential of $\mathrm{CO}_{2}$ laser and TiF4 solution on enamel adjacent to bracket. Then we compared various combinations of their application on the enamel.

\section{Methods}

In this experimental study, 75 freshly extracted bovine incisors were used. Bovine tooth structure is an alternative for human tooth according to its structure. ${ }^{5}$ After extraction, the remaining hard and soft tissues were removed using a sickle scaler and a surgical blade. Cleaned samples were stored in $0.5 \%$ chloramine- $\mathrm{T}$ (at $4^{\circ} \mathrm{C}$ ) for 7 days. The roots were removed from $5 \mathrm{~mm}$ below the cementoenamel junction using a laboratory hand piece and a diamond cutting disk under water cooling. The crowns were brushed with contra-angle hand piece and water. The samples were examined under a light microscope to ensure they were sound and caries free. In order to attach the brackets, the area of examination was covered with adhesive tape. We used common black electric tape duo to its adequate thickness; proper adaptation and coverage of the convex tooth surface to limit acid etching of the entire enamel surface causing an unintentionally initiating of enamel demineralization. The exposed enamel was etched for 40 seconds with 37\% phosphoric acid gel (Total Etch, MORVABON, Tehran, Iran), then rinsed with air-water spray for 30 seconds and thoroughly dried with compressed air. Metal orthodontic brackets for upper central (Ultratrimm Edgewise Bracket, DENTAURUM, Ispringen, Germany) were bonded to all teeth using a light cured composite bonding resin (Transbond XT, 3M Unitek, USA) following manufacturer's instruction. The excess resin flash was removed from around each bracket base with a sickle scaler before curing. The adhesive tapes were removed and any excessive adhesive residue from the tapes was removed with ethanol. The root canals were sealed with adhesive resin glue; a box with the same length of bracket and height of $4 \mathrm{~mm}$ was drawn with a standard graphite pencil cervical to each bracket. Then all teeth were painted with 2 layers of acid-resistant nail varnish on all surfaces except the box area cervical to bracket. The 75 teeth with their bonded brackets were then randomly divided into five groups $(n=15)$ : control group (C); laser group (L); titanium group (T); laser-titanium group (LT) and titanium-laser group (TL).

The teeth in the $\mathrm{C}$ group received no further treatment. Those in the $\mathrm{L}$ group were treated with pulsed $\mathrm{CO}_{2}$ laser (DEKA, Italy) emitting at $10.6 \mu \mathrm{m}$ wave length, 0.4 $\mathrm{W}$ power, $10 \mathrm{~Hz}$ repetition rate and $1 \mathrm{~ms}$ pulse duration with a spot size of $1 \mathrm{~mm}$. The whole rectangular area was irradiated using scanning method for 10 seconds. The laser spot moves in a horizontal line from left to right or right to left when it reaches the end, the next line will begin inferior to the previous line and in reverse direction. Samples in the T group were treated with $4 \% \mathrm{TiF} 4$ solution ( $\mathrm{pH}: 1.2)$. The solution was prepared freshly prior to its application on the enamel using $0.4 \mathrm{~g}$ of TiF4 powder (Titanium IV fluoride 98\%, Alfa Aesar, MA, USA) in 100 cc of distilled water. Two drops of the solution were applied on the enamel surface and remained undisturbed to dry out.

For the LT group, at first, the $\mathrm{CO}_{2}$ laser was irradiated (same as L group) then TiF4 solution was applied on the enamel (same as T group). The samples in the TL group were first treated with TiF4 solution (same as $\mathrm{T}$ group), and then $\mathrm{CO}_{2}$ laser was irradiated on the surface (same as L group).

We created artificial caries-like lesions in all teeth, using a $\mathrm{pH}$-cycling system that has been extensively used in dental caries and fluoride studies. ${ }^{1}$ This method has been shown to generate artificial caries like lesions and is a model for caries progression in the mouth. In order to create artificial caries-like lesions in all teeth, we implemented a $\mathrm{pH}$-cycling system. Each sample was individually immersed in $80 \mathrm{~mL}$ of demineralizing solution (pH 4.3) containing 0.075 molar of acetic acid (SIGMA CAS: $64-19-7), 2.0 \mathrm{mM}$ of calcium hydrogen phosphate (SIGMA CAS: $7757-93-9$ ) at $37^{\circ} \mathrm{C}$ for 6 hours, then rinsed with double-deionized water and immersed for 17 hours in $40 \mathrm{~mL}$ of a remineralizing solution ( $\mathrm{pH} 7.0)$ containing $20 \mathrm{mmol} / \mathrm{L}$ of sodium cacodylate (SIGMA CAS: 6131-99) as a buffer, $150 \mathrm{mmol} / \mathrm{L}$ of potassium chloride (MERCK CAS: 7447-40-7) to maintain ionic strength, $1.5 \mathrm{mmol} / \mathrm{L}$ of calcium nitrate (PANREAC CAS: 13477-34-4) and 0.9 $\mathrm{mmol} / \mathrm{L}$ of potassium phosphate (SIGMA CAS:7778-77$0)$ at $37^{\circ} \mathrm{C}$. We repeated this cycling of teeth through demineralizing and remineralizing solutions every 24 hours for 10 days, plus one day when the teeth remained in the remineralizing solution.

After the end of the $\mathrm{pH}$-cycling procedures, the samples were removed from the bottles and the amount of calcium released into the two solutions (de- and re-mineralization) was measured with an atomic absorption spec- 
troscopy (SpectrAA 220, Varian, Australia). Before the elements were determined, calibration was performed with calcium standard solutions (Panreac). From each solution $30 \mathrm{~mL}$ samples were taken in triplicate and three measurements of calcium to ensure the precision of the measurements; the mean value was calculated and calcium contents were measured in $\mu \mathrm{g} / \mathrm{mL}$.

In addition to spectroscopy analysis, enamel surface hardness was measured. The small area of intact enamel under the varnish was exposed and three indentations, at distances of $100 \mu \mathrm{m}$ from each other, were made in that area, in order to determine the hardness of sound enamel. The main hardness measurements were performed on exposed surface areas, which appeared free from any glazelike and laser defect structures (checked by $40 \times$ magnification). The mean hardness for sound and demineralized enamel were measured with a micro hardness device and the percentage of surface hardness change was calculated as follows.

Data analysis was performed using descriptive tests (eg, mean, median and standard deviation [SD]), one-way analysis of variance (ANOVA) and Tukey test in SPSS (SPSS; Chicago, Ill) version 15. A $\mathrm{P}<0.05$ was considered as statistical significance limitation.

\section{Results}

The mean \pm SD of calcium concentrations in demineralizing solutions are presented in Table 1. Calcium losses of LT, TL and T groups were significantly lower than those in the $\mathrm{L}$ and $\mathrm{C}$ groups $(P<0.05)$. Also, the laser group showed no significant difference with the control group $(P=0.679)$

Table 2 shows calcium concentrations in remineralizing solutions. The percentage of reduction in calcium loss was $78 \%$ in TL group and about $81 \%$ in LT and T groups. Also calcium analysis of remineralizing solutions showed significant lower calcium uptake in the last three groups (LT, TL and T) $(P=0.009, P=0.019$ and $P=0.006)$.

As it is showed in Table 3, the hardness measurements showed nearly the same results, and groups treated with titanium tetra fluoride showed significantly more surface hardness than control and laser groups $(P=0.002$ and $P=0.007)$. Laser irradiation seemed to have decreasing effect on surface hardness.

\section{Discussion}

The aim of this study was to assess the preventive effect of

Table 1. The Mean \pm SD of Calcium Concentrations in Demineralizing Solutions of Five Groups

\begin{tabular}{lcccc}
\hline & N & Mean & SD & SE \\
\hline Control & 15 & 32.0467 & 3.46531 & 0.89474 \\
Laser & 15 & 29.2000 & 5.59732 & 1.44522 \\
Laser-titanium & 15 & 5.7867 & 1.44710 & 0.37364 \\
Titanium-laser & 15 & 6.8333 & 1.72489 & 0.44536 \\
Titanium & 15 & 5.6933 & 2.61027 & 0.67397 \\
\hline
\end{tabular}

Abbreviations: SD, standard deviation; SE, standard error.
$\mathrm{CO}_{2}$ laser and TiF4 solution on caries prevention around orthodontic brackets. In order to have more accurate results, we used both solution analysis (Atomic Absorption Spectroscopy) and surface hardness test (Vickers Hardness Test). Both calcium analysis and microhardness test presented significantly less mineral loss for specimens treated with TiF4 solution than groups which were not treated with it.

The TiF4 solution was indeed able to cause an $81 \%$ decrease in the loss of calcium and significant increase in surface hardness compared to control group. This result is similar to other studies on this material. Exterkate and Ten Cate showed that up to $80 \%$ inhibition of demineralization could be achieved for the TiF4 derivative. ${ }^{14}$ Magalhães et al demonstrated the effect of TiF4 varnish on decreasing the demineralization and increasing the remineralization of previously sound and carious enamel. ${ }^{13}$ In our study, the tetrafluoride solutions were applied approximately at their natural $\mathrm{pH}(1.2)$, as it was previously shown that TiF4 is less effective in preventing enamel and dentin erosion when the $\mathrm{pH}$ is buffered to a higher value ( $\mathrm{pH}$ 3.5).$^{9-11}$ Penetration of fluorides into dental hard tissues is enhanced if the surface is slightly demineralized. ${ }^{12}$ Therefore, the low $\mathrm{pH}$ of $\mathrm{TiF} 4$ seems to be a boon in disguise due to the unique property of titanium ion. The acidic content of the solution made enamel surface chalky similar to etched enamel. The slight demineralization that occurs is expected to remineralize within a few weeks in the oral cavity. ${ }^{21}$ We did not use the varnish form; thus

Table 2. Multiple Comparisons

\begin{tabular}{|c|c|c|c|c|}
\hline & & $\begin{array}{c}\text { Mean } \\
\text { Difference }\end{array}$ & SE & $\boldsymbol{P}$ \\
\hline \multirow[t]{4}{*}{ Control } & Laser & 2.84667 & 1.69977 & 0.679 \\
\hline & Laser-titanium & 26.26000 & 0.96962 & 0.000 \\
\hline & Titanium-laser & 25.21333 & 0.99945 & 0.000 \\
\hline & Titanium & 26.35333 & 1.12018 & 0.000 \\
\hline \multirow[t]{4}{*}{ Laser } & Control & -2.84667 & 1.69977 & 0.679 \\
\hline & Laser-titanium & 23.41333 & 1.49274 & 0.000 \\
\hline & Titanium-laser & 22.36667 & 1.51229 & 0.000 \\
\hline & Titanium & 23.50667 & 1.59465 & 0.000 \\
\hline \multirow[t]{4}{*}{$\begin{array}{l}\text { Laser- } \\
\text { titanium }\end{array}$} & Control & -26.26000 & 0.96962 & 0.000 \\
\hline & Laser & -23.41333 & 1.49274 & 0.000 \\
\hline & Titanium-laser & -1.04667 & 0.58134 & 0.579 \\
\hline & Titanium & 0.9333 & 0.77061 & 1.000 \\
\hline \multirow[t]{4}{*}{$\begin{array}{l}\text { Titanium- } \\
\text { laser }\end{array}$} & Control & -25.21333 & 0.99945 & 0.000 \\
\hline & Laser & -22.36667 & 1.51229 & 0.000 \\
\hline & Laser-titanium & 1.04667 & 0.58134 & 0.579 \\
\hline & Titanium & 1.14000 & 0.80783 & 0.846 \\
\hline \multirow[t]{4}{*}{ Titanium } & Control & -26.35333 & 1.12018 & 0.000 \\
\hline & Laser & -23.50667 & 1.59465 & 0.000 \\
\hline & Laser-titanium & -0.09333 & 0.77061 & 1.000 \\
\hline & Titanium-laser & -1.14000 & 0.80783 & 0.846 \\
\hline
\end{tabular}

Abbreviation: SE, standard error. 
Table 3. The Mean \pm SD of Microhardness of Samples After Treatment

\begin{tabular}{lcccc}
\hline & N & Mean & SD & SE \\
\hline Control & 12 & 34.0333 & 8.93495 & 2.57930 \\
Laser & 12 & 43.0033 & 16.02470 & 4.62593 \\
Laser-titanium & 12 & 93.4083 & 19.43242 & 5.60966 \\
Titanium-laser & 12 & 84.3417 & 33.40834 & 9.64416 \\
Titanium & 12 & 107.3750 & 46.25440 & 13.35249 \\
\hline
\end{tabular}

Abbreviations: SD, standard deviation; SE, standard error.

the protection was not related to the covering layer of the varnish resin. The protective action of this compound incorporated into solution has been attributed not only to the action of fluoride ions as in other fluoride containing materials, but also to the action of titanium. According to previous studies, the low $\mathrm{pH}$ of $\mathrm{TiF} 4$ (around 1.2), is in favor of the linkage between titanium ions and oxygen of the phosphate group, and results in formation of a titanium dioxide glaze-like layer on the surface. ${ }^{12,13}$

In this experiment, laser treatment did not show important effect on reducing demineralization, and groups which were treated with both titanium and laser did not have significant difference with each other. Even in some cases laser reduced the inhibitory effect of TiF4 solution. The proposition that enamel melting by laser is desirable in order to increase resistance to acid attack is a matter of controversy. ${ }^{22}$ According to previous studies, morphological changes can be considered as an important factor which determines the kind of laser effect on enamel; and studies with high inhibition effect of $\mathrm{CO}_{2}$ laser didn't have obvious morphological changes on enamel..$^{1-3}$ One of these studies shows that the teeth which had less morphological changes due to laser irradiation showed higher inhibition rate than those with more cracks and fractures on surface. ${ }^{1}$ Irradiation of $\mathrm{CO}_{2}$ laser with our parameters caused morphological changes on surface as observed under binocular microscope. The surface was burned and did not appear to be uniform, and there were microfractures and exfoliations, which may leave inner areas of enamel uncovered and unprotected against acids. As said in other reports laser irradiation could result in firmer bond between fluoride containing particles on surface and enamel, and this leads to lower solubility of enamel. ${ }^{23}$ On the other hand, these micro fractures created susceptible areas to demineralization and they fall back the positive effect of laser. These defects are caused by the rapid expansion of water vapor in the organic matrix of enamel during laser treatment. ${ }^{22}$ The wavelength of $\mathrm{CO}_{2}$ laser has a high absorption coefficient on enamel surface and it is therefore more likely to affect the surface, even at relatively low powers. ${ }^{22}$ It is assumed that these morphological changes neutralized enamel hardening effects of laser and thus no significant difference where found when using laser.

Further in vivo studies should be performed to evaluate the clinical effect of TiF4 solution but low $\mathrm{pH}$ of native tetra fluoride solutions ( $\mathrm{pH} 1-2$ ) has to be considered as major drawback, since it might cause adverse side effects on oral soft tissues during application. The use of gel with higher viscosity or the varnish form of this substance will facilitate its control in clinical experiments, and gingival protection is necessary if the acidic form of the solution is used.

Adjusting laser parameters at rates leading to no obvious morphological changes makes it easy to harden the enamel against acid after bonding brackets. It is not easy to produce the same morphological features just by following parameters and there are some other handling parameters which has effect on enamel, such as the distance of laser device with tooth and beam diameter, and speed of operator's hand movement. In order to achieve this, specimens should be observed under microscope after a pilot irradiation, and the process should be continued for other specimens till morphological changes are desirable.

\section{Conclusion}

Application of titanium tetra fluoride $4 \%$ solution on enamel can inhibit as much as $87 \%$ of subsequent caries like lesion progression. When using $\mathrm{CO}_{2}$ laser, care must be taken to minimize morphological changes such as cracks and fusion on surface. These changes could make enamel sub surface susceptible to acid penetration.

\section{Conflict of Interests}

We had not any conflict of interests during this project.

\section{Acknowledgment}

This research was founded and supported by a grant from Dental Research Center, Dentistry Research Institute, Tehran University of Medical Sciences (Grant No: 15992). The authors would like to thank Dr. Mohammad Javad Kharazi Fard for his contribution in performing the statistical analysis of this study.

\section{References}

1. Kantorowitz Z, Featherstone JD, Fried D. Caries prevention by $\mathrm{CO}_{2}$ laser treatment: dependency on the number of pulses used. J Am Dent Assoc. 1998;129(5):585-591.

2. Esteves-Oliveira $\mathrm{M}$, Zezell DM, Meister $\mathrm{J}$, et al. $\mathrm{CO}_{2}$ Laser (10.6 microm) parameters for caries prevention in dental enamel. Caries Res. 2009;43(4):261-268. doi: $10.1159 / 000217858$.

3. Esteves-Oliveira M, Zezell DM, Ana PA, Yekta SS, Dentine caries inhibition through $\mathrm{CO}(2)$ laser $(10.6 \mu \mathrm{m})$ irradiation and fluoride application, in vitro. Arch Oral Biol. 2011;56(6):533-539. doi:10.1016/j.archoralbio.2010.11.019.

4. Rodrigues LK, Nobre Dos Santos M, Featherstone JD. In situ mineral loss inhibition by $\mathrm{CO}_{2}$ laser and fluoride. J Dent Res. 2006;85(7):617-621.

5. Souza-Gabriel AE, Colucci V, Turssi CP, Serra MC, Corona SA. Microhardness and SEM after $\mathrm{CO}(2)$ laser irradiation or fluoride treatment in human and bovine enamel. Microsc Res Tech. 2010;73(11):1030-1035. doi:10.1002/ jemt.20827.

6. van der Veen MH, Mattousch T, Boersma JG. Longitudinal development of caries lesions after orthodontic treatment evaluated by quantitative light-induced fluorescence. Am J 
Orthod Dentofacial Orthop. 2007;131(2):223-228.

7. Øgaard B. White Spot lesions during orthodontic treatment: mechanisms and fluoride preventive aspects. Semin Orthod. 2008;14(3):183-193. doi:10.1053/j. sodo.2008.03.003.

8. ten Cate JM, van Loveren C. Fluoride mechanisms. Dent Clin North Am. 1999;43(4):713-742.

9. Jardim JJ, Pagot MA, Maltz M. Artificial enamel dental caries treated with different topical fluoride regimes: an in situ study. J Dent. 2008;36(6):396-401. doi:10.1016/j. jdent.2008.02.010.

10. Lee YE, Baek HJ, Choi YH, Jeong SH, Park YD, Song KB. Comparison of remineralization effect of three topical fluoride regimens on enamel initial carious lesions. J Dent. 2010;38(2):166-171. doi:10.1016/j.jdent.2009.10.002.

11. Sudjalim TR, Woods MG, Manton DJ, Reynolds EC. Prevention of demineralization around orthodontic brackets in vitro. Am J Orthod Dentofacial Orthop. 2007;131(6):705.e1-9.

12. Wiegand A, Hiestand B, Sener B, Magalhães AC, Roos M, Attin T. Effect of TiF4, ZrF4, HfF4 and AmF on erosion and erosion/abrasion of enamel and dentin in situ. Arch Oral Biol. 2010;55(3):223-228. doi:10.1016/j. archoralbio.2009.11.007.

13. Magalhães AC, Comar LP, Rios D, Delbem AC, Buzalaf MA. Effect of a $4 \%$ titanium tetrafluoride (TiF4) varnish on demineralisation and remineralisation of bovine enamel in vitro. J Dent. 2008;36(2):158-162. doi:10.1016/j. jdent.2007.12.001.

14. Exterkate RA, Ten Cate JM. Effects of a new titanium fluoride derivative on enamel de- and remineralization. Eur J Oral Sci. 2007;115(2):143-147.

15. Farhadian N, Miresmaeili A, Eslami B, Mehrabi S. Effect of fluoride varnish on enamel demineralization around brackets: an in-vivo study. Am J Orthod Dentofacial Orthop. 2008;133(4 Suppl):S95-S98. doi:10.1016/j. ajodo.2006.09.050
16. Demito CF, Vivaldi-Rodrigues G, Ramos AL, Bowman SJ. The efficacy of a fluoride varnish in reducing enamel demineralization adjacent to orthodontic brackets: an in vitro study. Orthod Craniofac Res. 2004;7(4):205-210.

17. Wiegand A, Magalhães AC, Attin T.Is titanium tetrafluoride (TiF4) effective to prevent carious and erosive lesions? A review of the literature. Oral Health Prev Dent. 2010;8(2):159-164

18. Wiegand A, Magalhães AC, Navarro RS, et al. Effect of titanium tetrafluoride and amine fluoride treatment combined with carbon dioxide laser irradiation on enamel and dentin erosion. Photomed Laser Surg. 2010;28(2):219226. doi:10.1089/pho.2009.2551.

19. Levy FM, Magalhães AC, Gomes MF, Comar LP, Rios D, Buzalaf MA. The erosion and abrasion-inhibiting effect of $\mathrm{TiF}(4)$ and $\mathrm{NaF}$ varnishes and solutions on enamel in vitro. Int J Paediatr Dent. 2012;22(1):11-6. doi:10.1111/j.1365263X.2011.01151.x.

20. Magalhães AC, Kato MT, Rios D, Wiegand A, Attin T, Buzalaf MA. The effect of an experimental 4\% Tif4 varnish compared to $\mathrm{NaF}$ varnishes and $4 \% \mathrm{TiF} 4$ solution on dental erosion in vitro. Caries Res. 2008;42(4):269-274. doi: $10.1159 / 000135672$.

21. Wahengbam P, Tikku AP, Lee WB. Role of titanium tetrafluoride $(\mathrm{TiF}(4))$ in conservative dentistry: A systematic review. J Conserv Dent. 2011;14(2):98-102. doi:10.4103/0972-0707.82598

22. González-Rodríguez A, de Dios López-González J, del Castillo Jde D, Villalba-Moreno J. Comparison of effects of diode laser and $\mathrm{CO}_{2}$ laser on human teeth and their usefulness in topical fluoridation. Lasers Med Sci. 2011;26(3):317-324. doi:10.1007/s10103-010-0784-y.

23. Tepper SA, Zehnder M, Pajarola GF, Schmidlin PR. Increased fluoride uptake and acid resistance by $\mathrm{CO}_{2}$ laserirradiation through topically applied fluoride on human enamel in vitro. J Dent. 2004;32(8):635-641. 